\title{
Up-grading of Locally Produced Metallurgical Grade Silicon (MG-Si)
}

\author{
Heba H.M. Ali ${ }^{1 *}$, Mohamed El-Sadek ${ }^{1}$, Mohamed B. Morsi ${ }^{1}$, Kamilia A.El- \\ Barawy $^{1}$, Rabab M. Abou-Shahba ${ }^{2}$ \\ ${ }^{1}$ Minerals Technology Department - Pyrometallurgy Lab., Central Metallurgical \\ Research \& Development Institute (CMRDI), Cairo, Egypt, ${ }^{2}$ Faculty of Science \\ (girls), Al-Azhar University, Egypt
}

\begin{abstract}
T OCALLY produced metallurgical grade silicon (MG-Si 97\%) was upgraded by using wet-

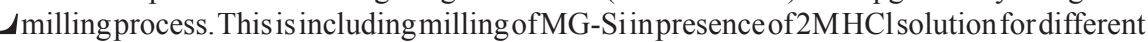
time periods up to $60 \mathrm{~min}$. The effect of milling time in $\mathrm{HCl}$ solution was studied. Soaking of the milled products (at optimum milling time $15 \mathrm{~min}$.) with continuous stirring in the same solution of $2 \mathrm{M} \mathrm{HCl}$ for interval time up to $240 \mathrm{~min}$. also were investigated. Finally, the effect of addition of $2 \mathrm{M} \mathrm{HF}$ to the milled product was discussed. The leached samples were investigated by X-ray fluorescence (XRF), and scanning electron microscope (SEM). It was found that, $99.92 \%$ purity of MG-Si was achieved after 15 min milling time with $2 \mathrm{M} \mathrm{HCl}$ followed by addition $2 \mathrm{M} \mathrm{HF}$ for 240 min with continuous stirring. About $97 \%$ removal efficiency of the impurities was obtained.
\end{abstract}

Keywords: MG-Si, up-grading of MG-silicon, purification of silicon, acid leaching.

\section{Introduction}

In recent years, solar grade silicon (SOG-Si), purified from metallurgical grade silicon (MG-Si) as the feedstock of the PV industry, has been in great demand, with a rapid development of more than $30 \%$ annual growth rate [1-4]. The dominant method for purification of silicon is Siemens process. But it is a highly complicated and considered as of high cost process. The development of a cheap process for the production of solar grade silicon (SOG$\mathrm{Si}$ ) of $99.9999 \%$ purity is a challenging task and the subject of recent world's wide research. These developed methods involve separation of impurities from silicon by acid leaching, slag refining, vacuum distillation, directional solidification [5-7]. Among the proposed alternative purification methods is the acid leaching of pulverized MG-Si. The principle of the acid leaching process is that most of the metallic elements present as impurities in MG-Si have a high segregation coefficient in silicon. Thus, in spite of the high solubilities of the impurities in the molten silicon, they have small solubilities in the solid and remain concentrated at the grain boundaries. Upon grinding the $\mathrm{MG}-\mathrm{Si}$, fracture occurs mainly at grain boundaries exposing the impurities to the action of the acids [8]. The acid leaching enables purification of silicon, with the advantages of simple equipment, low cost, low energy consumption and dealing with a large quantity [9]. The past studies are almost focused on the effect of impurity removal of a variety of specific methods and the optimum process parameters. Due to the use of different materials, the results of different studies are quite different [9-12]. Recently, Sahu and Asselin [13] investigated the effects of using two different oxidizing agents, such as ferric chloride and ammonium persulfate, on the purification of MG-Si by leaching with hydrochloric acid. The addition of an oxidizing agent improved the extraction of impurities from the MG-Si. Also, the pretreatment of $\mathrm{MG}-\mathrm{Si}$ to remove certain metallic impurities has a significant effect on the refining process. The purification of MG-Si can be achieved also by calcination and quenching before leaching, in addition to complexation with glycerin as a ligand [14].

The aim of this paper is the utilization of MG-Si produced by reduction smelting technique in EAF at Central Metallurgical Research\& Development Institute (CMRDI) to obtain upgrading of the purity value of MG-Si. This is applied through studying the factors affecting the wet milling in presence of hydrochloric acid solution, and the effect of hydrofluoric acid addition. 


\section{Experimental}

The chemical analysis of the starting MGsilicon $(\sim 97 \%)$ is shown in Table 1 , the main impurities are $\mathrm{Fe}, \mathrm{Ca}, \mathrm{Al}, \mathrm{Ti}$, and $\mathrm{Cu}$ with the presence of minor amounts of $\mathrm{P}, \mathrm{Na}$, and $\mathrm{S}$. The silicon lumps were crushed by a jaw crusher, and subjected to sieve analysis. The milling process was carried out using planetary ball mill (P400 Germany) and ball powder ratio (BPR) of 10:1. The leaching process was initiated during the milling process by milling $-0.5 \mathrm{~mm}+2.5 \mathrm{~mm}$ fraction with $100 \mathrm{ml}$ of $2 \mathrm{M} \mathrm{HCl}$ solution which called wet-milling process. Also, all experiments were carried out with liquid-solid weight ratio of 10: 1. After each experiment, the sample was filtered and washed with de-ionized water before drying. The metallic impurities were chemically analyzed by XRF. The flow sheet of the wet milling process of MG-Si is shown in Fig.1.

The removal efficiency of impurities $\left(\mathrm{R}_{\mathrm{M}}\right)$ can be calculated according to the following equation:

$$
\mathrm{R}_{\mathrm{M}}=\left[\frac{\mathrm{M}_{\mathrm{Raw} \mathrm{Si}}-\mathrm{M}_{\text {Purified Si }}}{\mathrm{M}_{\mathrm{Raw} \mathrm{Si}}}\right] \times 100
$$

Where,

$\mathrm{M}_{\text {Raw Si }}=$ Content of total impurities in raw MG$\mathrm{Si}$

$\mathrm{M}_{\text {Purified Si }}=$ Content of total impurities in purified $\mathrm{Si}$

TABLE 1. Chemical analysis of MG-Si.

\section{Results and Discussion}

\section{Effect of milling time}

To study the effect of milling periods, about 10 $\mathrm{g}$ of MG-Si sample was subjected to milling with $100 \mathrm{ml}$ of $2 \mathrm{M} \mathrm{HCl}$ solution in planetary vertical ball mill for different periods 15,30 , and $60 \mathrm{~min}$. Figure 2 shows the effect of milling period with $2 \mathrm{M} \mathrm{HCl}$ solution on the concentrations of the impurities which present in MG-Si as Al, Fe, and $\mathrm{Ca}$. It is noticed that, the concentrations of the metallic impurities decreased up to milling time 15 min. and no significant result was obtained after this period. It is also observed that the removal of impurities was better for calcium, aluminum and worst for iron. This result may be due to: by increasing the milling time, the particle size of MG-Si was reduced to less than $45 \mu \mathrm{m}$ after milling time $60 \mathrm{~min}$., where some impurities tend to segregate to grain boundaries or to interstitial positions. These impurities are very friable so can be removed more effectively [9]. Moreover, some impurity phases (as $\mathrm{Fe}$ ) adsorbed at the silicon surface which became more difficult to be removed from this finer fraction by further washing during the leaching process.

Figure 3 illustrates the morphologies of the silicon samples examined by SEM after milling for $15 \mathrm{~min}$. in $2 \mathrm{M} \mathrm{HCl}$ solution. The images show that the surface of MG-Si has many grooves

\begin{tabular}{|l|c|c|c|c|c|c|c|c|c|c|}
\hline Elements & $\mathbf{A l}$ & $\mathbf{F e}$ & $\mathbf{C a}$ & $\mathbf{N a}$ & $\mathbf{N i}$ & $\mathbf{P}$ & $\mathbf{M n}$ & $\mathbf{C u}$ & $\mathbf{S}$ & $\mathbf{T i}$ \\
\hline Concentration/ ppmw & 3930 & 11530 & 10850 & 130 & 350 & 280 & 280 & 1020 & 120 & 1860 \\
\hline
\end{tabular}

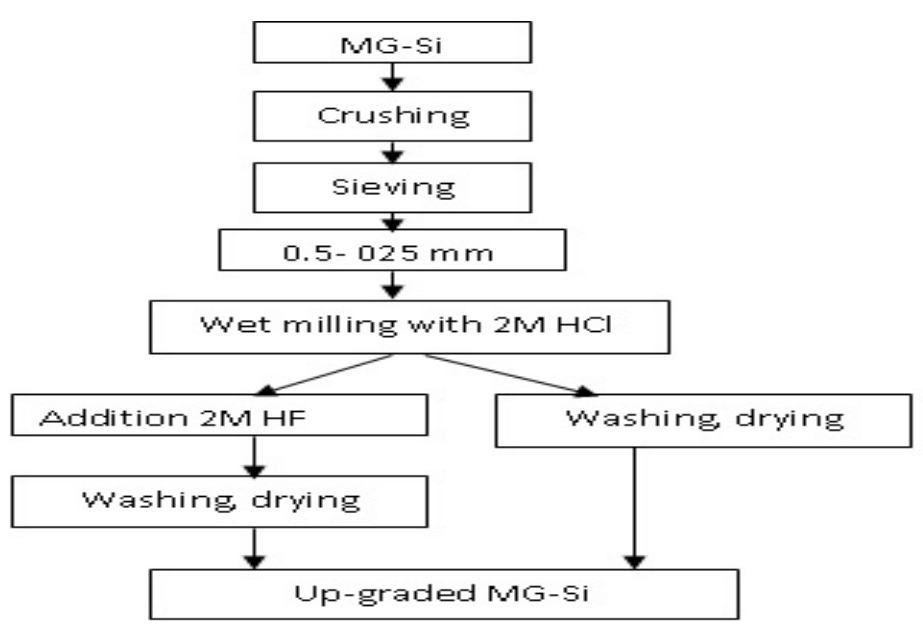

Fig. 1. Flow sheet of the wet milling of MG-Si

Egypt. J. Chem. 61, No. 1 (2018) 




Fig. 2. The concentrations of $\mathrm{Al}, \mathrm{Fe}$, and $\mathrm{Ca}$ impurities for the MG-Si after milling for different periods with $2 \mathrm{M}$ HCl solution.

and scrapes after milling process. So, the milling process causing a large material stress, which lead to make many cracks and defects along the crystal boundaries. Therefore, impurities are exposed on the surface of the silicon and dissolved in acids, which is beneficial for their removal by acid leaching process.

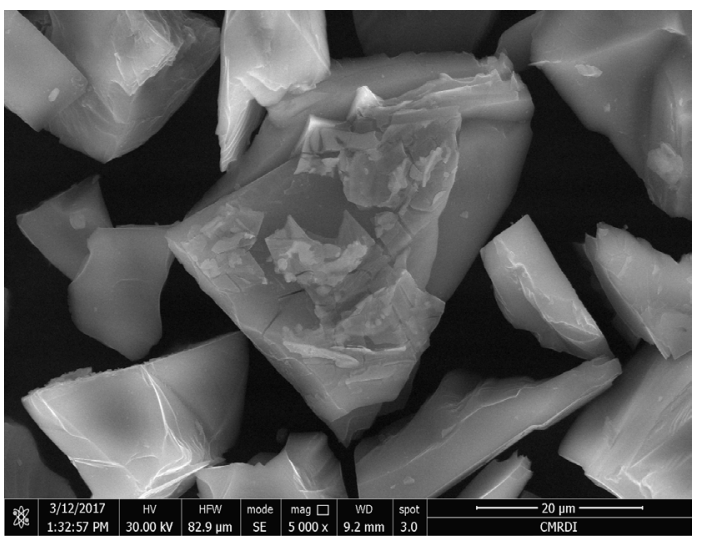

Fig. 3. SEM analysis for MG-Si samples after milling with $2 \mathrm{M} \mathrm{HCl}$ for $15 \mathrm{~min}$.

\section{Effect of soaking time in $\mathrm{HCl}$ solution after milling step}

The MG-Si samples which milled in $2 \mathrm{M}$ $\mathrm{HCl}$ solution for $15 \mathrm{~min}$. (wet milling step) were soaked in the same solution for different periods up to $240 \mathrm{~min}$. with continues stirring at room temperature. Figure 4 shows the effect of soaking time in $2 \mathrm{M} \mathrm{HCl}$ for different periods on the metallic impurities concentrations as $\mathrm{Al}, \mathrm{Fe}$, and $\mathrm{Ca}$ which present in the milled MG-Si. It was observed that the impurities concentrations decreased by increasing the soaking period in $\mathrm{HCl}$ solution. Also, the removal efficiency for $\mathrm{Fe}, \mathrm{Al}$, and $\mathrm{Ca}$ was increased.

The SEM analysis of the milled MG-Si after soaking in $2 \mathrm{M} \mathrm{HCl}$ for $240 \mathrm{~min}$. was shown in Fig. 5. From SEM analysis there are many grooves, scrapes and agglomeration of the impurities at the surface of silicon after milling and soaking processes. These agglomerations of impurities in separated forms are caused during the milling process. From XRF analysis, the purity of obtained silicon was increased from $98.3 \%$ to $99.0 \%$ after soaking in the same solution for $240 \mathrm{~min}$. it is concluded that the milling assisted leaching process with further soaking in the same solution is better for calcium and aluminum than iron. This phenomenon may be due to less solubility intermetallics of iron phases [15]. It was mentioned that aluminum-containing intermetallic compounds often contain calcium, so consistency of the removing trend between aluminum and calcium is better than between aluminum and iron. Therefore the removal of impurities by $\mathrm{HCl}$ is better for aluminum, calcium and worst for iron $[8,9,15]$.

\section{Effect of HF addition on the milled MG-Si}

The wet milled samples by $2 \mathrm{M} \mathrm{HCl}$ at optimum milling time (15 min.) were subjected to leaching process with $2 \mathrm{M} \mathrm{HF}$ solution. HF was added directly to the samples after milling step. The effect of HF addition directly to the milled 
samples for different periods 60, 120, and 240 $\mathrm{min}$. at room temperature was investigated. Figure 6 shows the impurities concentration of $\mathrm{Al}, \mathrm{Fe}$ and $\mathrm{Ca}$ in MG-Si samples after milling step followed by adding HF for different periods up to $240 \mathrm{~min}$. A sharp decrease in the impurities concentration can be seen after adding HF to the solution, also the removal efficiency increased to about $97 \%$ for iron, aluminum and calcium respectively at room temperature. It is worthy to notice that, $99.92 \%$ purity of the silicon was achieved after addition of $2 \mathrm{M} \mathrm{HF}$ and this is in agreement with many authors $[9,15]$. The addition of HF directly to the sample after milling accelerates the removal of the metallic impurities of MG-Si than using $\mathrm{HCl}$ only.

Figure 7 illustrates the morphologies of the MG-Si after milling with 2M HCL for 15 min. then adding $2 \mathrm{M} \mathrm{HF}$ for $240 \mathrm{~min}$. It was clear that the surface of the MG-Si appears smooth and

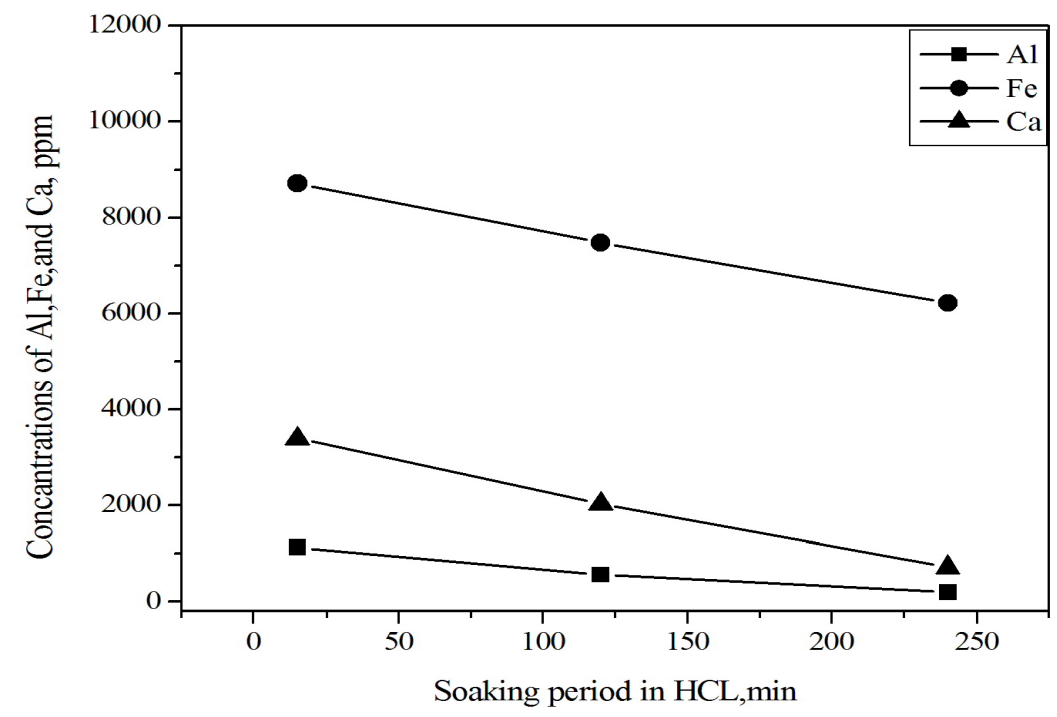

Fig. 4. The impurities concentrations of $\mathrm{Al}, \mathrm{Fe}$, and Ca after milled MG-Si with $2 \mathrm{M} \mathrm{HCl}$ for 15 min. then soaked in the same solution for different periods

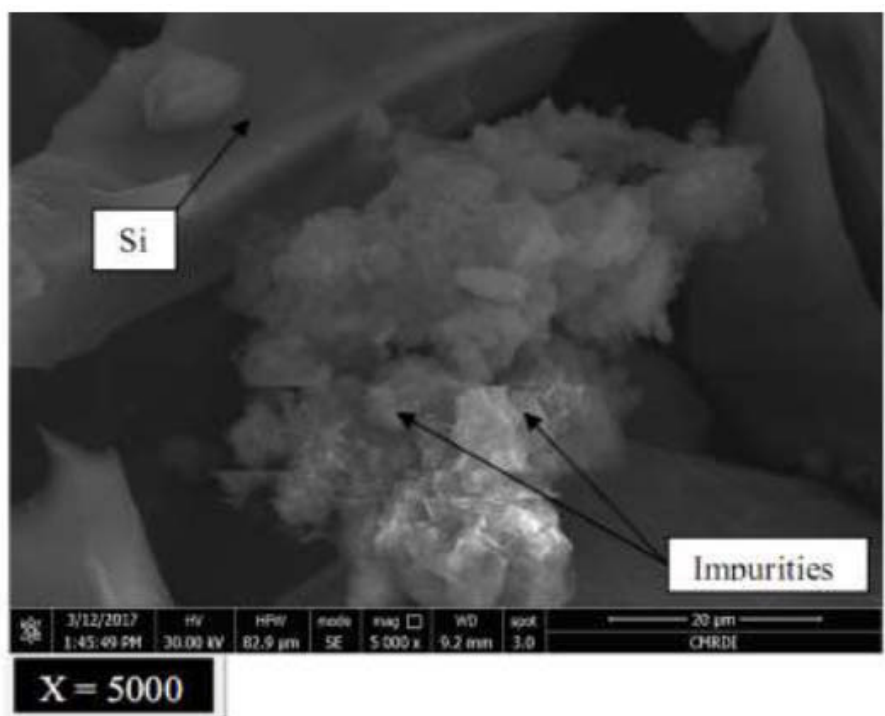

Fig. 5. SEM analysis for MG-Si after milling $15 \mathrm{~min}$. then soaking in the same solution of $2 \mathrm{M}$ HCl for $240 \mathrm{~min}$. 


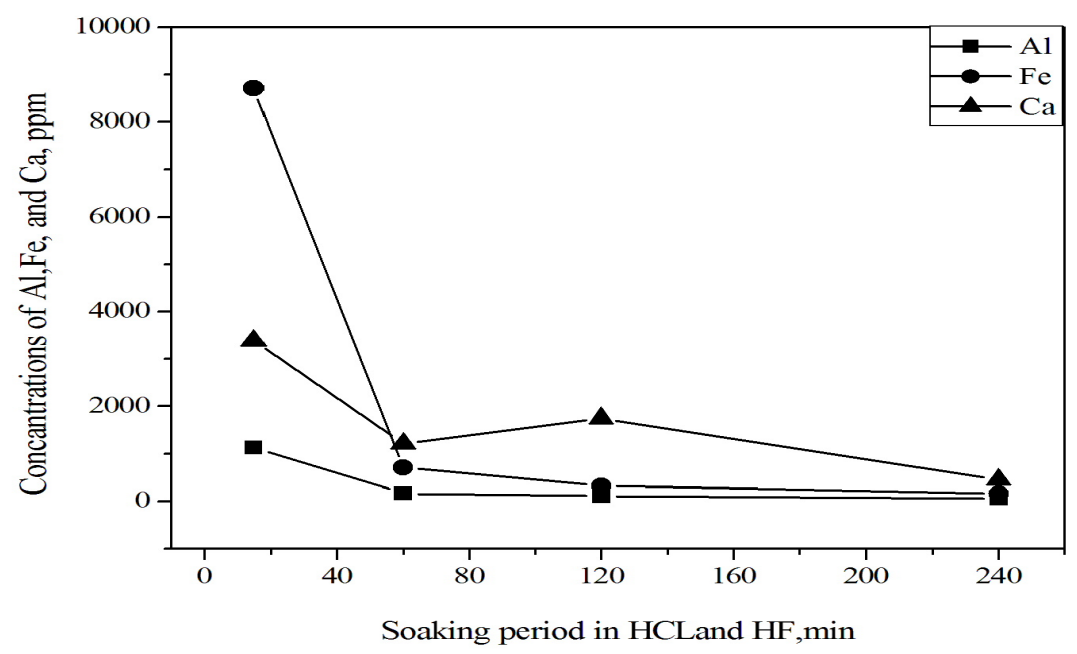

Fig. 6. The impurities concentrations of $\mathrm{Al}$, Fe, and Ca in MG-Si after milling 15 min. with $2 \mathrm{M}$ HCl followed by addition 2M HF for different periods.

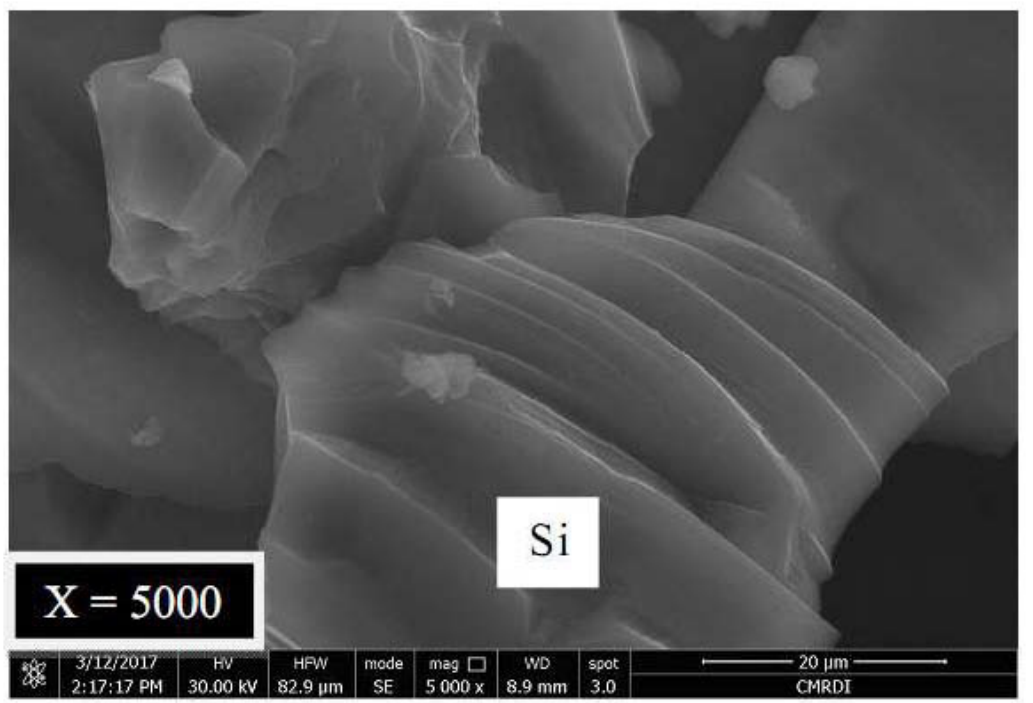

Fig. 7. SEM analysis for MG-Si powders after milling with $2 \mathrm{M}$ HCL for 15 min. followed by adding $2 \mathrm{M}$ HF for 240 min.

clean and there are many grooves and scrapes on the surface of the silicon so the crystal boundary was not obvious. This change may be attributed to the milling process which enhances the removal of metallic impurities by acid leaching process.

\section{Conclusions}

1. The wet milling with $2 \mathrm{M} \mathrm{HCl}$ is a pretreatment step and a novel method for up-grading of MG-Si and used to increase the efficiency of the leaching process
2. This method proved that the optimum liberation size of silicon is ranged from $+90 \mu \mathrm{m}$ to $+45 \mu \mathrm{m}$.

3. This study concluded that the wet milling with acid improves the leaching and up-grading process of MG-Si. This is because the wet milling causes groves, scraps, and micro inclusions. Also the phases of unstable impurities are dissociated and exposed at the surface of silicon particle which enhances its removal by acid leaching.

4. The addition of $\mathrm{HF}$ improves the effect of $\mathrm{HCl}$ 
on the removal of the impurities.

5. The addition of hydrofluoric acid (2M HF) to hydrochloric acid $(2 \mathrm{M} \mathrm{HCl})$ resulted in refining of MG-Si (99.92\%) at room temperature for $240 \mathrm{~min}$. after milled with $2 \mathrm{M} \mathrm{HCl}$ solution for $15 \mathrm{~min}$ as a pretreatment step for the leaching process. The removal efficiency of impurities also enhanced to about $97 \%$.

\section{References}

1. Wen, Y., Hu Y. D., and Shan T. L., Improvements of separating process in polycrystalline $\mathrm{Si}$ production by modified Siemens arts and crafts, Chemical Industry and Engineering, 25(2), 154-159, (2008).

2. Zeng, Y.L., Ding, G. J., and Liao, M.L., Research progress on new technology of reduction of polysilicon from Siemens, Sichuan Nonferrous Metal. 2, 1-4, (2009).

3. Sarti, D., and Einhaus, R., "Silicon feedstock for the multi-crystalline photovoltaic industry", Sol. Energy Mater. Sol. Cells. 72 (1-4): 27,( 2002).

4. Swanson, R. M.,A vision for crystalline silicon photovoltaic, Prog. Photovolt. Res. 14 (5), 443,(2006).

5. Lu, D., Ma, W. H., Wu, J. J., and Ma, X. D., Research on removal of impurities in metallurgical grade silicon by metallurgical method, Master Thesis, Dalian University of Technology. 23(3), 3033,(2009).

6. Morita, K., and Mikib, T., Thermodynamics of solar-grade-silicon refining, Intermetallics, 11(11), 1111-1117, (2003).

7. Lu, D., Ma, W. H., and Wu, J. J., Materials Review, vol. 23 (3), p. 30-33, (2009).
8. Santos, I. C., Goncalves, A. P., Santos, C. S., Almeida, M., Afonso, M. H., and Cruz, M. J., Purification of metallurgical grade silicon by acid leaching, Hydrometallurgy, 23, 237-246, (1990).

9. Mai, Y., Wenhui, M. A., Keqiang, X., Wang, T., Zhang, H., and Qiang, L., Comparative study on removal of $\mathrm{Fe}, \mathrm{Al}$ and $\mathrm{Ca}$ from MG-Si by acid leaching, Advanced Materials Research, 581-582, 831-835, (2012).

10. Yu, Z. L., Ma, W. H. and Dai, Y. N., Trans. Nonferrous Met. Soc. China, Vol. 17, p. s1030-s1033, (2007).

11. Juneja, J.M. and Mukherjee, T.K., A study of the purification of metallurgical grade silicon. Hydrometallurgy. 16, 69-75. (1986).

12. Lashgari, V.A. and Yoozbashizadeh, H., Purification of metallurgical grade silicon by acid leaching, ASM Science Journal, 1(1), 37-41. (2007).

13. Sahu, S. K. and Asselin, E., Effect of oxidizing agents on the hydrometallurgical purification of metallurgical grade silicon, Hydrometallurgy, 121124: 120-125, (2012).

14. Anglezio, C., Servant, C. and Dubrous, F., Characterization of metallurgical grade silicon. Journal of Materials Research. 5(9), 1894-1899, (1990).

15. Sun, Y. H., Qi-Hui, Y., Chang-Juan, G., Hong-Yu, C., Lang, X., David, F., Qi-Wen, L. and Chun-Mei, Y., Purification of metallurgical-grade silicon via acid leaching, calcinations and quenching before boron complexation. Hydrometallurgy, 139, 64-72, (2013).

(Received 28/11/2017; accepted 20/12/2017) 


\section{رفع جودة السيليكون التجاري المتنج محليا}

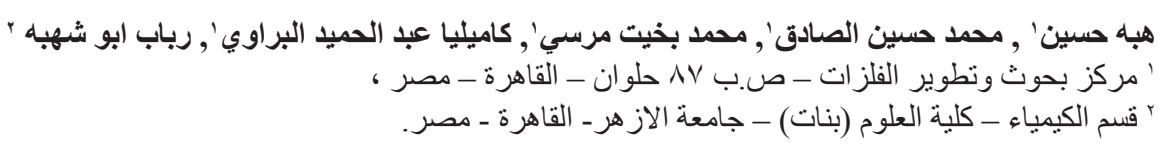

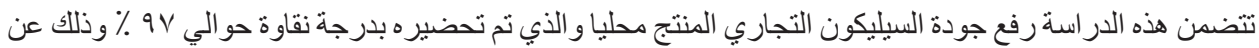

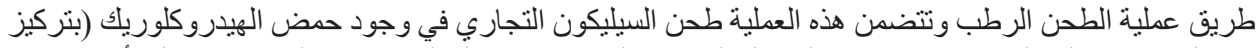

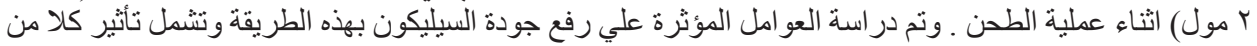



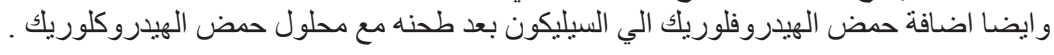



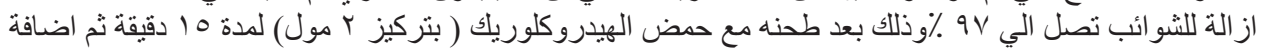

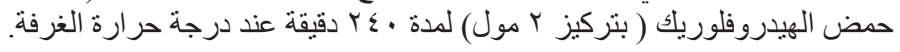

